\title{
Dominant Bacterial and Archaeal Phyla Associated with Top Soils Sourced from Commercial Farm Holding in Delta State, Nigeria
}

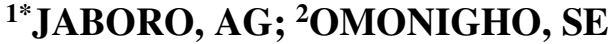

\begin{abstract}
${ }^{*}$ Precious Life Medical Centre, Unity Road, Games Village, Kaura District, FCT-Abuja, Nigeria.
\end{abstract} \\ ${ }^{2}$ Department of Microbiology, Faculty of Life Science, University of Benin, Benin City, Edo State, Nigeria. \\ *Corresponding author Email: Jaborograndy@gmail.com, Tel: 07033212230, 08052530353
}

\begin{abstract}
The dominant bacteriological and archaeal phyla of compounded soils sourced from a commercial farm estate located in Amukpe town and a nearby control in Adavware community both in Delta State, were evaluated with the aid of Next Generation Sequencing (NGS) protocols. The residual herbicide and pesticide composition of the bulked soils were also determined using gas chromatography (GC) and electron capture detector (ECD). Total concentrations of the extracted DNA were 6.83 and $6.65 \mathrm{ng} / \mu \mathrm{l}$ for the control and experimental soils. Nine (9) bacterial phyla; Proteobacteria, Actinobacteria, Chloroflexi, Firmicutes, Verrucomicrobia, Planctomycetes, Bacteroidetes Acidobacteria, and Elusimicrobia were observed in the control soil. Thirteen (13) bacterial phyla; Elusimicrobia, Fibrobacteres Lentisphaerae, Armatimonadetes, Cyanobacteria/Chloroplast, Bacteroidetes, Actinobacteria, Proteobacteria, Chloroflexi, Firmicutes, Acidobacteria, Planctomycetes and Verrucomicrobia were detected in the experimental soil. Two (2) archaeal phyla; Euryarchaeota, and Diapherotrites were detected both the experimental and control soil, whilst an additional archaeal phylum; Woesearchaeota was present in only the experimental soil. The total organochloride phosphate component of the experimental soil was $1.4 \mu \mathrm{g} / \mathrm{Kg}$ and $0.4 \mu \mathrm{g} / \mathrm{Kg}$ for the control soil respectively.
\end{abstract}

\section{DOI: https://dx.doi.org/10.4314/jasem.v23i1.2}

Copyright: Copyright $\odot 2019$ Jaboro and Omonigho. This is an open access article distributed under the Creative Commons Attribution License (CCL), which permits unrestricted use, distribution, and reproduction in any medium, provided the original work is properly cited.

Dates: Received: 03 November 2018; Revised: 19 January 2019; Accepted 22 January 2019

Keywords: Amukpe, Next Generation Sequencing, Adavware, bacterial and archaeal phyla

Agriculture is reliant on herbicide usage for the control of weeds in crops and pastures to maximize yields and economic benefits to sustain an increasing world population (Zabaloy et al., 2011). Herbicides are biologically active compounds (Baboo et al., 2013), also commonly known as weed killers, are chemical substances employed in the control of unwanted plants. Herbicides vary in their potential to persist in soil and herbicide families that have persistent members include the triazines, uracils, phenylureas, sulfonylureas, dinitroanilines, isoxazolidinones, imidazolinones, and certain plant growth regulators belonging to the pyridine family (Curran, 2001).The environmental fate of herbicides has been a matter of recent concern given that only a small fraction of the chemicals reach the target organisms (Pimentel, 1995), which has led to the possibility of potential impacts of residual herbicides in soil and water on human, animal and crop health (Zabaloy et al., 2011). While herbicides are very important to agriculture, under certain circumstances they could act as pollutants that can deteriorate soils, ground waters and surface waters. While most herbicides are not intentionally applied onto soil, they can enter the soil environment from 1) direct interception of spray by the soil surface during early season or post-harvest applications, 2) runoff of the herbicide from vegetation and 3) leaching from dead plant material. The herbicide concentration may vary from a few $\mu \mathrm{g}$ to mg per $\mathrm{kg}$ soil, as most of the applied chemical is retained within the top $5 \mathrm{~cm}$ of soil (Zabaloy et al., 2011).

Soil microbial biomass has been regarded as an active nutrient pool to plants and is known to play an important role in nutrient cycling and decomposition in ecosystem (De-Lorenzo et al., 2001). A healthy soil borne microbial population can stabilize the edaphic ecological system due to their ability to regenerate nutrients which aid plant growth. Any change in their population and activity could affect nutrient cycling as well as availability of nutrients, which indirectly affect productivity and other soil functions (Wang et al., 2008). Comparatively, the practice of large scale commercial farming involving the application of large quantities of herbicides is lesser in Nigeria when compared to the Americas and Europe. However, there are individuals or groups which have been involved in commercial farming ventures in several parts of both Northern and Southern Nigeria and in the course of daily operations utilize various types of pre and post emergence herbicides to control the growth and spread of weeds in their farm holdings. While the focus of most pollution impact based researches has been on the environmental effect of petroleum exploration and allied industries, there is a need to evaluate the impact of continuous herbicide usage on the health of non-target soil microbial habitat. This is very relevant as a consequence of the critical roles, majority of these soil based microflora play in the 
recycling of life sustaining elements such as carbon and nitrogen. The objective of this study is to evaluate the dominant bacteriological and archaeal phyla associated with top soils sourced from commercial farm holding in Delta state, southern Nigeria.

\section{MATERIALS AND METHODS}

Description of study area: Sapele Local Government Area of Delta State, Nigeria is a cosmopolitan area documented to comprise of several farming communities such as Adagbrasa, Amukpe, Adavware, Elume, Ogiedi, Ughorhen and Ikeresan respectively. Some of these farming communities play host to oil fields and flow stations. Amukpe is located within Longitude E 5' 42' 55.76" and Latitude N 5 51' $38.75^{\prime}$ with elevation above sea level being 11 meters. The vegetation is typical of the rainforest except for drainage streams where swampy areas exists (Fig. 1). The commercial farm holding located in Amukpe, is an integrated farm registered as a company limited by guarantee in September, 2005, by Delta State Government. The farm was modeled around the Songhai-Parakuo of the Republic of Benin.

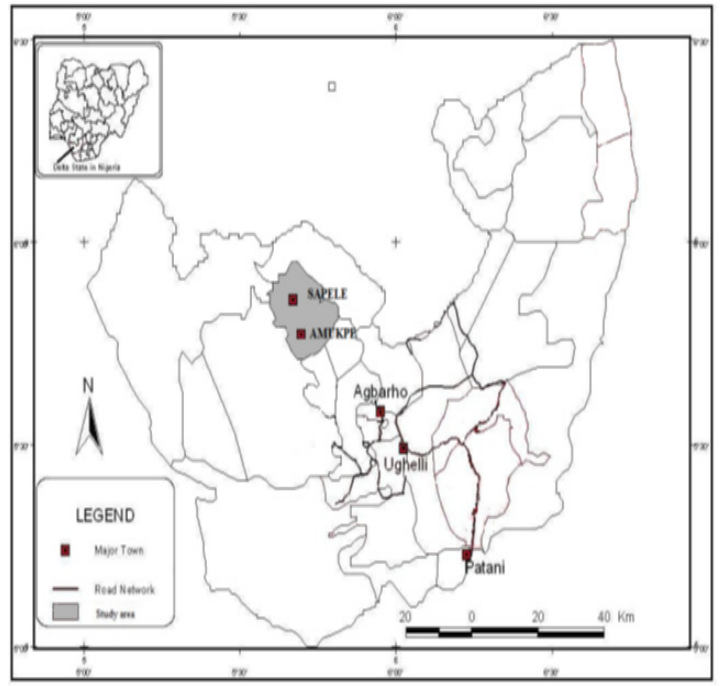

Fig 1: Map of Delta State, Nigeria, showing Amukpe in Sapele LGA, insert is the map of Nigeria (Atakpo, 2013)

Collection of top soils: Top soils were collected from an active agricultural land within the premises of the commercial farm sited in Amukpe, Sapele LGA, Delta State. With the aid of a soil auger, $100 \mathrm{~kg}$ of the top soil were obtained from the respective sampling stations; Station one; watermelon and tomatoes farm Station two; Maize farm Station three; Cassava farm at depth $0-15 \mathrm{~cm}$. Another $100 \mathrm{~kg}$ of uncontaminated fallow soil which have been left for an unknown time period, which served as the control were collected from Adavware community, near Amukpe. These soils samples were placed in labeled sterile polyethylene bags and transported to the laboratory for analysis.
Protocol for metagenomic analysis using next generation sequencing (NGS: Total DNA was extracted from $2 \mathrm{~g}$ of each soil samples labeled "experimental" (for compounded soils from Songhai Farms, Amukpe) and "Control" (for compounded soils from Adavware community), using the NucleoSpin Soil Kit. The quantity and quality of the extracted DNA was assessed by NanoDrop Spectrophotometry and Qubit Fluorometry. PCR amplifications were performed for each DNA sample using the V3_V4 primer set to amplify bacterial DNA. PCR reaction products were evaluated via agarose gel electrophoresis. Each PCR product was cleaned using Agencourt AMPure XP beads. Unique index adapters were ligated to each PCR product to generate a V3_V4 library and an ITS1 library for each sample. Libraries were evaluated by agarose gel electrophoresis. Each Library was cleaned using Agencourt AMPure XP beds and subsequently evaluated by Qubit fluorometry and Agilent 2100 Bioanalyzer.

V3_V4 libraries were size-selected using BluePippin for a target fragment range of $450-850 \mathrm{bp}$. Final libraries were abalyzed by Qubit fluorometry and Agilent 2100 Bioanalyzer. The final libraries were pooled with compatible libraries from other projects and loaded into the Illumina MiSeq to generate an average of at least $0.5 \mathrm{M}$ PE300 reads for each library. Raw Illumina data was converted into .fastq format and de-multiplexed. Reads that were short $(\mathrm{N}<100)$ or of poor quality $(\mathrm{Q}<20)$ were filtered out. The forward and reverse Illumina read for each cluster (amplicon molecule) were collapsed to generate a full sequence of the amplicon. Phylogenic assignment of 16S rRNA reads were performed with the RDP classifer (Quail, 2009).

Determination of the residual soil herbicide and pesticide content: The residual herbicide and pesticide value of the respective soils was ascertained using Gas Chromatography (GC) system equipped with an Electron Capture Detector (ECD) and an HP1 capillary column.. The operating conditions of the GC column were; Injector Temperature: $250{ }^{\circ} \mathrm{C}$, Oven Temperature: $100^{\circ} \mathrm{C}$, Injection Mode: Splitless, Flow Control Mode: Linear velocity, Oven program: Rate; $10{ }^{\circ} \mathrm{C}$, Temperature; $100^{\circ} \mathrm{C}$ to $200^{\circ} \mathrm{C}$ and Hold time; $1 \mathrm{~min}$ to 2 mins. The specific herbicide and pesticide residues analyzed in the respective soils include; Aldrin (a-BHC, b-BHC and d-BHC, $\gamma$-BHC (Lindane), $\alpha$-Chlordane, $\gamma$-Chlordane, atrazine, $\mathrm{p}, \mathrm{p}$ DDD, p,p-DDE, p,p-DDT 4,4-DDT, diedrin, endosulfan 1, endosulfan 11, endosulfan sulfate, endrin, endrin aldehyde, heptachlor, heptaclor epoxide, methoxychlor, diazinon, phosphoro methyl glycine, TCMX, carbamate and decachlorobiphenyl. The concentration of each analyte range in a sample was calculated directly from the instrument using the Data Analysis Software. 


\section{RESULTS AND DISCUSSION}

The concentrations of the extracted DNA were 6.83 and $6.65 \mathrm{ng} / \mu \mathrm{l}$ for the control and experimental soils respectively (Table 1). The Qubit fluorometric analyzed DNA had concentration of 0.072 and 0.057 for the control and experimental soils respectively (Table 2). The total DNA volume of the fluorometeric analyzed V3_V4 libraries were; $227 \mathrm{ng} / \mu \mathrm{l}$ and 448 $\mathrm{ng} / \mu 1$ for the control V3_V4 and experimental V3_V4 respectively (Table 3 ). The total DNA volume of the fluorometeric analyzed V3_V4 final sized-selected libraries were; $118 \mathrm{ng} / \mu \mathrm{l}$ and $194 \mathrm{ng} / \mu \mathrm{l}$ for the control V3_V4 and experimental V3_V4 respectively (Table 4). The raw and trimmed reads were; 502,247 and 477,581 for control V3_V4 and 500,442 to 495,149 for experimental V3_V4 respectively (Table 5). The merged reads were 446,182 and 399,388 for both control V3_V4 and experimental V3_V4 respectively (Table 5).

Table 1: Concentration and purity of extracted prokaryotic DNA (ng/ $\mu$ l) from the control (Adavware) and (Songhai Farms) farmed soils

\begin{tabular}{llllll}
\hline Sample ID & Concentration & $\mathbf{A}_{260}$ & $\mathbf{A}_{280}$ & $\mathbf{A}_{\text {260 }} / \mathbf{A}_{\mathbf{2 8 0}}$ & $\mathbf{A}_{\mathbf{2 6 0}} / \mathbf{A}_{\mathbf{2 3 0}}$ \\
\hline Control & 6.83 & 0.137 & 0.087 & 1.57 & 0.53 \\
Experiment & 6.65 & 0.133 & 0.075 & 1.78 & 0.57 \\
\hline
\end{tabular}

Table 2: Qubit fluorometry (ng/ $\mu \mathrm{l})$ analysis of extracted DNA from the control (Adavware) and experimental (Songhai Farms) soil samples

\begin{tabular}{llll}
\hline Sample ID & Concentration & Volume $(\boldsymbol{\mu l})$ & DNA $(\mathbf{n g})$ \\
\hline Control & 0.072 & 50 & 3.6 \\
Experiment & 0.057 & 50 & 2.9 \\
\hline
\end{tabular}

Table 3: Qubit fluorometry (ng/ $\mathrm{\mu l}$ ) analysis of V3_V4 libraries from the control (Adavware) and experimental (Songhai Farms) soil

\begin{tabular}{llll}
\multicolumn{4}{c}{ samples } \\
\hline Sample ID & Concentration & Volume $(\boldsymbol{\mu l})$ & Total DNA $(\mathbf{n g})$ \\
\hline Control_V3_V4 & 5.68 & 40 & 227 \\
Experimental_V3_V4 & 11.2 & 40 & 448 \\
\hline
\end{tabular}

Table 4: Qubit fluorometry (ng/ $\mu \mathrm{l}$ ) analysis of Final sized-selected libraries from the control (Adavware) and experimental (Songhai

\begin{tabular}{llll}
\multicolumn{4}{c}{ Farms) soil samples } \\
\hline Sample ID & Concentration & Volume $(\boldsymbol{\mu l})$ & Total DNA $(\mathbf{n g})$ \\
\hline Control_V3_V4 & 2.94 & 40 & 118 \\
Experimental_V3_V4 & 4.86 & 40 & 194 \\
\hline
\end{tabular}

Table 5: Summary of bioinformatics analysis from the control (Adavware) and experimental (Songhai Farms) soil samples

\begin{tabular}{llll}
\hline Sample ID & Raw Reads & Trimmed Reads & Merged Reads \\
\hline Control V3_V4 & 502,247 & 477,581 & 446,182 \\
Experimental V3_V4 & 500,442 & 495,149 & 399,388 \\
\hline
\end{tabular}

The result of the agarose electrophoresis of the PCR-1 products of the extracted DNA from both the control and experimental soil samples used for the next generation sequence is shown in figure 2 . The results of the initial and final size-selected Agilent 2100 bioanalyzer analysis of the control and experimental soil samples at the _V3_V4 and the initial bacterial DNA respectively are shown in figures 3 to figure 6 as an electropherogram.

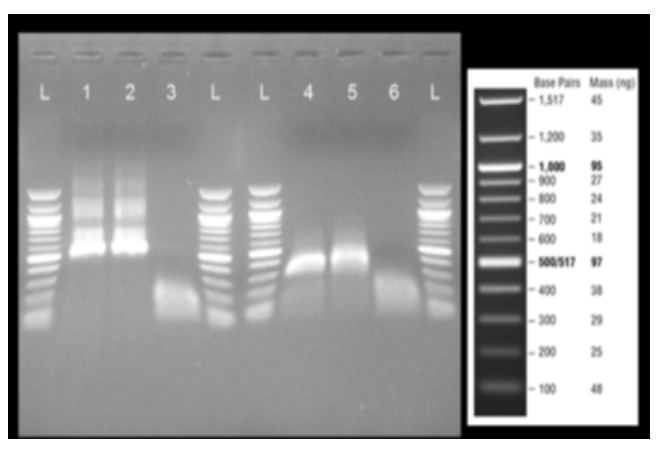

Fig. 2: Agarose gel electrophoresis of PCR-1 products of the extracted DNA from both the control (Adavware) and experimental (Songhai Farms) soil samples

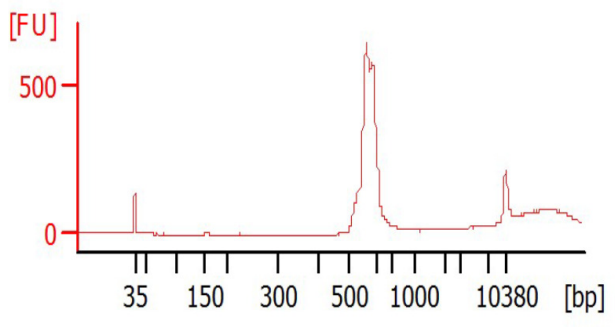

Fig. 3: Agilent 2100 Bioanalyzer analysis of the Control_V3_V4 region of the DNA from the control (Adavware) sample

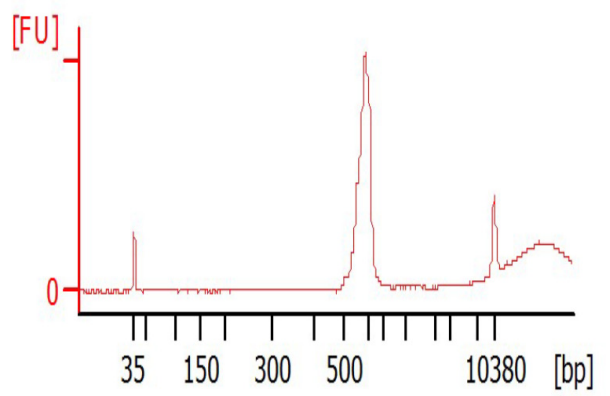

Fig. 4: Agilent 2100 Bioanalyzer analysis of the Experimental_V3_V4 region of the DNA from the experimental (Songhai Farm) sample 
Nine (9) bacterial phyla; Proteobacteria, Actinobacteria, Chloroflexi, Firmicutes, Verrucomicrobia, Planctomycetes, Bacteroidetes Acidobacteria, and Elusimicrobia were observed in the control soil (Table 6, Fig. 7 and 8) Methylohalomonas sp. and Pacearchaeota Incertae Sedis AR13 were the predominant bacterial and archaeal species present in the control soil (Fig. 6 and 7). Ktedonobacter sp. (10\%) and Methanomassilicoccus sp. (27\%) were the predominant bacterial and archaeal species present in the bulked experimental soil (Fig. 10). Thirteen (13) bacterial phyla; Elusimicrobia , Fibrobacteres Lentisphaerae Cyanobacteria/Chloroplast, Armatimonadetes, Actinobacteria Proteobacteria, Chloroflexi, Firmicutes, Acidobacteria, Planctomycetes and Verrucomicrobia were detected in the experimental soil (Table 6, Fig.10). Three (3) archaeal phyla; Euryarchaeota, Woesearchaeota and Diapherotrites were detected in the experimental soil (Table 7, Fig. 10, 11 and 12).

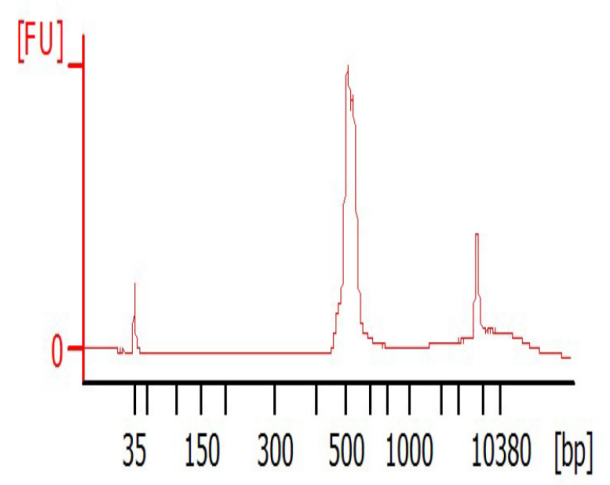

Fig. 5: Agilent 2100 Bioanalyzer analysis of Final size-selected Control_V3_V4 region of the DNA from the control (Adavware) sample

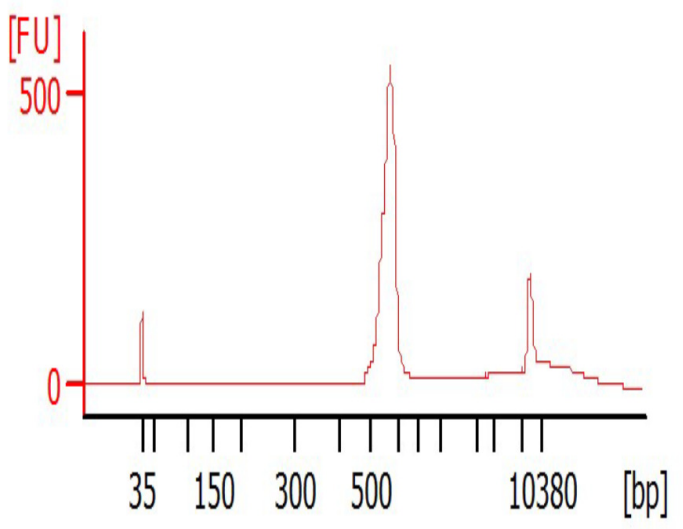

Fig. 6: Agilent 2100 Bioanalyzer analysis of Final size-selected Experimental_V3_V4 region of the DNA from the experimental (Songhai Farms) sample
Table 6: Bacterial phyla distribution in the control (Adavware) and experimental (Songhai farms) soil samples

\begin{tabular}{lcc}
\hline \multirow{1}{*}{ Phyla } & \multicolumn{2}{c}{ Bacterial } \\
\cline { 2 - 3 } & Control & Experimental \\
Actinobacteria & soil & soil \\
Acidobacteria & + & + \\
Bacteroidetes & + & + \\
Chloroflexi & + & + \\
Elusimicrobia & + & + \\
Firmicutes & + & + \\
Planctomycetes & + & + \\
Proteobacteria & + & + \\
Verrucomicrobia & + & + \\
Armatimonadetes & + & + \\
Cyanobacteria/Chloroplast & - & + \\
Fibrobacteres & - & + \\
Lentisphaerae & - & + \\
\hline
\end{tabular}

Table 7: Archaeal phyla distribution in the control (Adavware) and experimental (Songhai farms) soil samples.

\begin{tabular}{ccc}
\hline & \multicolumn{2}{c}{ Bacterial } \\
\cline { 2 - 3 } Phyla & Control soil & Experimental soil \\
Diapherotrites & + & + \\
Euryarchaeota & + & + \\
Woesearcheota & - & + \\
\hline
\end{tabular}

Expectedly, application of next generation sequencing (NGS) procedures revealed the presence of a thriving bacterial and archaeal community in both the control and the experimental soils. Wilson and Piel (2013) earlier stated the culturable part of the bacterial biome may be a poor representative of the community inhabiting the soil. Jacobsen and Hjelms $\varnothing$, (2014) further reported that amongst the culture independent methods which utilize $16 \mathrm{~S}$ rRNA gene as a molecular marker, which included; DGGE, T-RFLP and RAPD, their ability to describe changes in the bacterial community were, in terms of resolution, inferior to next generation sequencing (NGS) techniques. The archaeal domain was lesser in magnitude for the experimental soil in comparison with the control soil.

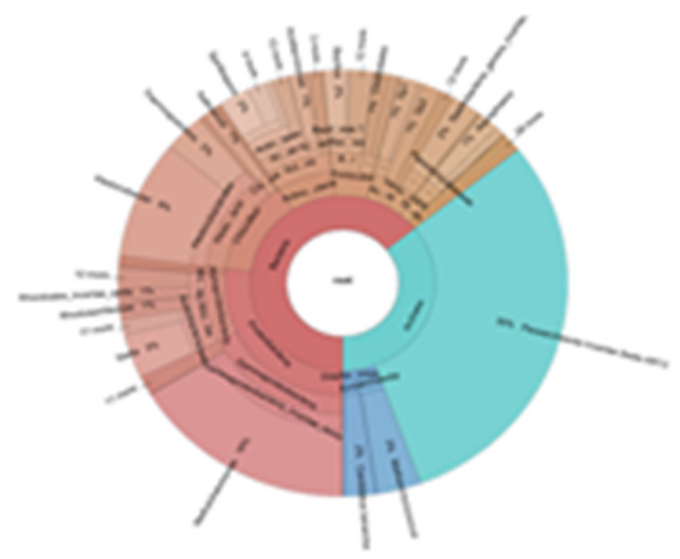

Fig. 7: Percentage occurrence of bacterial and archaeal domains present in the bulked control soil 


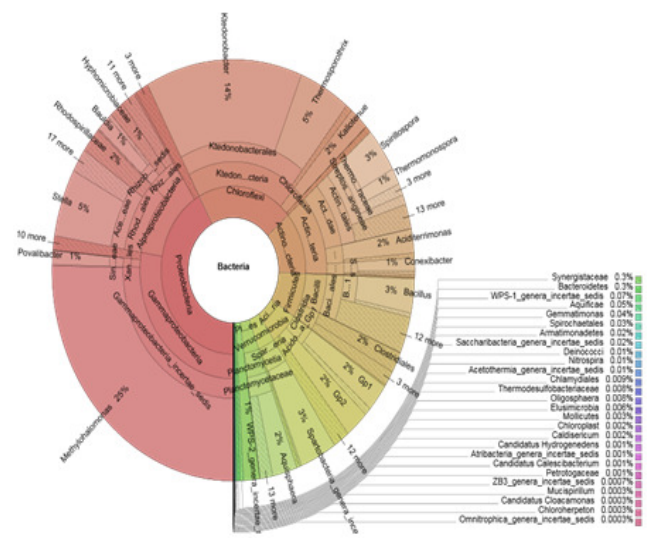

Fig. 8: Percentage occurrence of the bacterial domain present in the bulked control soil

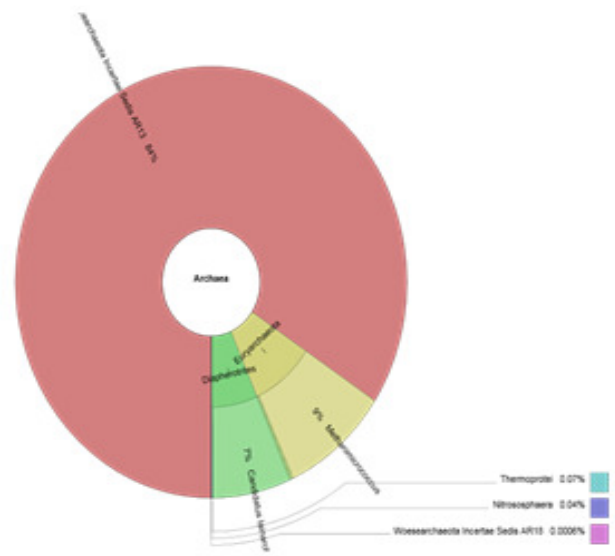

Fig. 9: Percentage occurrence of the archaeal domain present in the bulked control soil

This phenomenon could be attributed to the impact of anthropogenic land usage patterns as per the current intensive utilization of the experimental soil for agricultural purposes. Pereira de Castro et al. (2016) reported that seasonal fluctuations of soil-water uptake could also impact directly on the prevailing soil borne bacterial and archaeal diversity. Fierer et al. (2012) reported that changes in $\mathrm{pH}$, temperature, and nutrient availability could also influence soil microbial community structure. García-Orenes et al. (2013) opined that land management in agricultural areas had a significant impact on soil microbial attributes. Evidently, the increased bacterial diversity recorded for the experimental soil indicated that the number of bacterial phyla associated with this soil was numerically greater than the total number of bacterial phyla detected for the control soil. This trend might be reflective of the profound changes that occurred with the soil borne prokaryotic flora as a consequence of the either anthropogenic or environmental impacts on the terrestrial niche. Janssen (2006) reported that by using molecular identification based on 16S rRNA, nine bacterial phyla (Proteobacteria, Acidobacteria, Actinobacteria, Verrucomicrobia, Bacteroidetes, Chloroflexi, Planctomycetes, Gemmatimonadetes, and Firmicutes) are generally dominant in a soil environment.

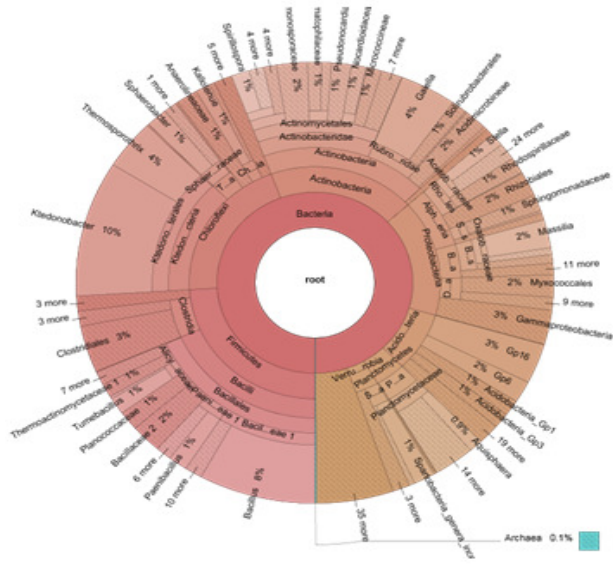

Fig. 10: Percentage occurrence of bacterial and archaeal domains present in the bulked experimental soil

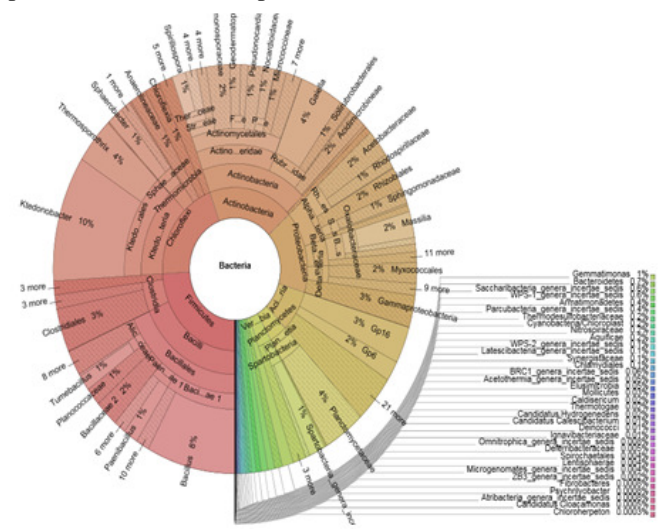

Fig. 11: Percentage occurrence of the bacterial domain present in the bulked experimental soil

This assertion is in agreement with findings from this research, however, the phyla Elusimicrobia was present in soil samples from Adavware community while Armatimonadetes, Cyanobacteria/Chloroplast, Fibrobacteres and Lentisphaerae were present in the bulked soils collected from the commercial farm estate, Delta State.

Next generation sequencing results from this research are in tandem with Kim et al., (2014) who also reported, that previous studies on soil bacterial communities detected worldwide: in the Americas (e.g., Brazil, Canada, Florida, and Illinois) (Roesch et al., 2007), in German forests and grasslands (Nacke et al., 2011), and in forests in China, Japan, and Malaysia (Singh et al., 2012; Tripathi et al., 2012; Miyashita et al., 2013; Singh et al., 2013) through the pyrosequencing method were three major phyla, namely; Acidobacteria, Actinobacteria, and Proteobacteria. Kim et al. (2014) observed that the overall major soil borne bacterial phyla in Dokdo (a volcanic island, east of mainland South Korea) were Proteobacteria, Actinobacteria, and Acidobacteria with an average relative abundance of $34.3 \%, 23.9 \%$, and $16.1 \%$, however, this observation is at variance with results from this study (Adavware; $42.0 \%, 12 \%$, 
$6 \%)$ and the farm holdings, Amukpe $(16 \%, 19 \%, 8$ $\%$ ) respectively. The detection of two (2) archaeal phyla; Euryarchaeota and Diapherotrites in both the bulked control and experimental soil is in tandem with an earlier report by Pereira de Castro et al. (2016) which indicated the presence of these two (2) archaeal phyla in soils collected from four vegetation physiognomies in Central Brazil.

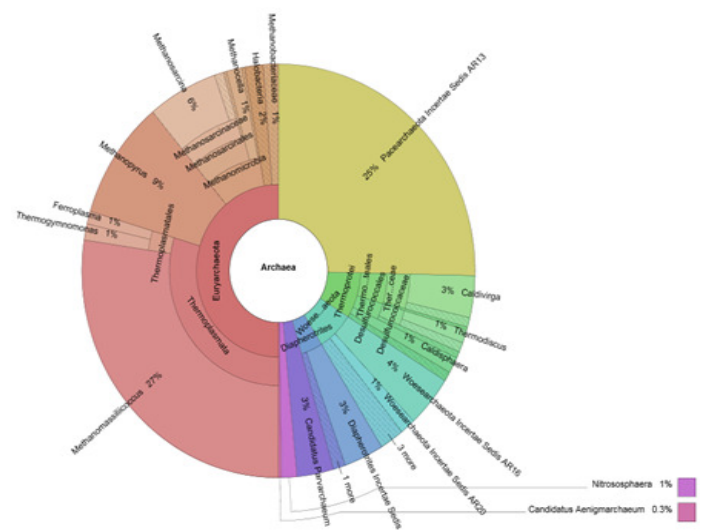

Fig. 12: Percentage occurrence of the archaeal domain present in the bulked experimental soil

Table 8: Residual organochloride herbicide and pesticide content of the control (Adavware) and experimental (Songhai Farms) Soils

\begin{tabular}{lcc}
\hline \multicolumn{1}{c}{ Component } & Control & Experimental \\
\hline Aldrin a-BHC & 0.0000 & 0.0000 \\
b-BHC & 0.0000 & 0.0000 \\
d-BHC & 0.0000 & 0.0002 \\
Gamma-BHC (Lindane) & 0.0003 & 0.0007 \\
Alpha-Chlordane & 0.0000 & 0.0000 \\
Gamma-Chlordane & 0.0000 & 0.0000 \\
Atrazine & 0.0000 & 0.0000 \\
p,p-DDD & 0.0001 & 0.0000 \\
p,p-DDE & 0.0000 & 0.0003 \\
p,p-DDT 4,4-DDT & 0.0000 & 0.0000 \\
Diedrin & 0.0000 & 0.0000 \\
Endosulfan 1 & 0.0000 & 0.0000 \\
Endosulfan 11 & 0.0000 & 0.0000 \\
Endosulfan sulfate & 0.0000 & 0.0000 \\
Endrin & 0.0000 & 0.0000 \\
Endrin aldehyde & 0.0000 & 0.0000 \\
Heptaclor & 0.0000 & 0.0000 \\
Heptaclor epoxide & 0.0000 & 0.0000 \\
Methoxychlor & 0.0000 & 0.0002 \\
Diazinon & 0.0000 & 0.0000 \\
Phosphoro methyl glycine & 0.0000 & 0.0000 \\
TCMX & 0.0000 & 0.0000 \\
Carbamate & 0.0000 & 0.0000 \\
Decachlorobiphenyl & 0.0000 & 0.0000 \\
\hline TOTAL OCP $(\mu \mathrm{g} / \mathrm{Kg})$ & 0.4000 & 1.4000 \\
\hline
\end{tabular}

Residual organochloride herbicide content of both the herbicide impacted soil and the control revealed minute traces of $\triangle$-BHC (Aldrin), $\mathrm{\gamma}$-BHC (Lindane), p,p-DDD [1,1-Dichloro-2,2-bis-(p-chlorophenyl)ethane $], \quad \mathrm{p}, \mathrm{p}-\mathrm{DDE} \quad[1,1-$ Dichloro-2,2-bis(pchlorophenyl)-ethylene], and Methoxychlor with total $\mathrm{OCH}$ being $1.4 \mu \mathrm{g} / \mathrm{Kg}$ in the experimental soil sample and $0.4 \mu \mathrm{g} / \mathrm{Kg}$ in the control (Table 8). A survey of the commercial farm estate at Amukpe, Delta State was conducted in March, 2016 under the supervision of the farm manager, who confirmed the usage of herbicide on the farm to control weeds and pesticides to control pest. The herbicide employed were mainly those of the glyphosate group sourced from the open market. Glyphosate is a non- selective, broad spectrum herbicide and crop desiccant. It is an organophosphorus compound, specifically a phosphonate, used to kill weed especially annual broadleaf weeds and grasses that compete with crops. Glyphosate $\left(\mathrm{C}_{3} \mathrm{H}_{8} \mathrm{NO}_{5} \mathrm{P}\right)$ has a water solubility of $1.01 \mathrm{~g} / 100 \mathrm{ml}$ and acidity $\mathrm{pKa}<2,2.6,5.6,10.5$ and traded under the several names which include; Roundup $\AA$, Rodeo $\AA$ and Pondmaster ${ }^{\circledR}$ respectively.

Conclusion: The bacterial and archaeal biomes of bulked soils collected from the commercial farm estate located at Amukpe and fallow land sited at Adavware both in Sapele LGA, Delta State was evaluated and the presence of several prokaryotic phyla were documented. A notable limitation of this research was the inability to establish a direct link between the compositions of the soil microbiome with its functional activity.

\section{REFERENCES}

Baboo, M; Pasayat, M; Samal, A; Kujur, M; Maharana, JK; Pate, AK (2013). Effect of four herbicides on soil organic carbon, microbial biomass-c, enzyme activity and microbial populations in agricultural soil. Inter. J. Res. Environ. Sci. Technol. 3(4): 100-112.

Curran, SW (2001). Persistence of herbicides in soil. Agronomy Facts 36, U.S. Department of Agriculture, Washington D.C. Pp 4.

De Lorenzo, ME; Scott, GL; Ross, PE (2001). Toxicity of pesticides to aquatic microorganisms: a review. Environ. Toxicol. Chem. 20: 84-98.

Fierer, N; Lauber LC; Ramirez, SK; Zaneveld, J; Bradford, AM; Knight, R (2012). Comparative metagenomics, phylogenic and physiological analyses of soil microbial communities across nitrogen gradients. Inter. Soc. Micro. Ecol. 6: 1007-1017.

Garcia-Orenes, F; Morugan-Coronado, A; Zornoza, R; Scow, K (2013). Changes in soil microbial community structure influences by agricultural management practices in a Mediterranean agroecosystem. PLoS ONE 8(11): 1-9.

Jacobsen, CS; Hjelmsø, MH (2014). Agricultural soils, pesticides and microbial diversity Curr. Opinion Biotechnol. 27:15-20.

Janssen, PH (2006). Identifying the dominant soil bacterial taxa in libraries of $16 \mathrm{~S}$ rRNA and $16 \mathrm{~S}$ 
rRNA genes. Appl. Environ. Microbiol. 72: 1719-1728.

Kim, YE; Yoon, H; Kim, M; Nam, YJ; Kim H; Seo, Y; Lee, GM; Kim, Y; Kong, WS; Kim, J G; Seu, YB (2014). Metagenomic analysis of bacterial communities on Dokdo Island. J. Gen. Appl. Microbiol. 60: 65-74.

Miyashita, NT; Iwanaga, H; Charles, S; Diway, B; Sabang, J; Chong, L (2013). Soil bacterial community structure in five tropical forests in Malaysia and one temperate forest in Japan revealed by pyrosequencing analyses of $16 \mathrm{~S}$ rRNA gene sequence variation. Genes and Gene. Syst. 88: 93-103.

Nacke, H; Thürmer, A; Wollherr, A; Will, C; Hodac, L; Herold, N; Schoning, I; Schrumpf, M; Daniel, $R$ (2011). Pyrosequencing-based assessment of bacterial community structure along different management types in German forest and grassland soils. PLoS One. 6 (2):1-15.

Pereira de Castro, A; Sartori da Silva, MRS; Quirino, BF; da Cunha Bustamante, MM; Krüger, RH (2016). Microbial Diversity in Cerrado Biome (Neotropical Savanna) Soils. PLoS ONE 11(2): 116.

Pimentel, D (1995). Amount of pesticides reaching target pest: environmental impacts and ethics. $J$. Agric. Environ. Ethics. 8:17-29.

Quail, MA; Swerdlow, H; Turner, DJ (2009). Improved protocols for illumine genome analyzer sequencing system. Curr Protc Hum Genetic. $18: 2$
Roesch, LF; Fulthorpe, RR; Riva, A; Casella, G; Hadwin, AK (2007). Pyrosequencing enumerates and contrasts soil microbial diversity. ISME J. 1: 283-290.

Singh, D; Shi, L; Adams, JM (2013). Bacterial diversity in the mountains of South-West China: Climate dominates over soil parameters. $J$. Microbiol. 51: 439-447.

Singh, D; Takahashi, K.; Kim, M; Chun, J; Adams, JM (2012). A hump-backed trend in bacterial diversity with elevation of Mount Fuji, Japan. Micro. Ecol. 63: 429-437.

Tripathi, BM; Kim, M; Singh, D; Lee-Cruz, L; LaiHoe, A; Ainuddin, AN; Go, R; Rahim, RA; Husni, MH; Chun, J; Adams, JM (2012). Tropical soil bacterial communities in Malaysia: $\mathrm{pH}$ dominates in the equatorial tropics too. Micro. Ecol. 64: 474-484.

Wang, QK; Wang, SL; Liu, YX (2008). Responses to $\mathrm{N}$ and $\mathrm{P}$ fertilization in a young Eucalyptus dunnii plantation; microbial properties, enzyme activities, and dissolved organic carbon. Appl. Soil Ecol. 40: 484-490.

Wilson, MC; Piel, J (2013). Metagenomic approaches for exploiting uncultivated bacteria as a resource for novel biosynthetic enzymology. Chem. Biol. 20: 636-647.

Zabaloy, CM; Zanini, PG; Bianchinotti, V; Gomez, MA; Garland, JL (2011). Herbicides in the soil environment: Linkage between bioavailability and microbial ecology. In: Larramendy, M (ed). Herbicides, Theory and Applications, Intech Europe, Rijeka. p. 162-192. 